\title{
A SAÚDE E O PRINCÍPIO DA DIGNIDADE DA PESSOA HUMANA: POSSIBILIDADES E DESAFIOS PARA ATUAÇÃO DO SERVIÇO SOCIAL
}

\author{
Daniela Cacciatore Silveira
}

Faculdade de Ciências Econômicas de Apucarana, Especialista em Gestão de Políticas Sociais. E-mail: dany_cacciatore@yahoo.com.br

\section{RESUMO \\ Este artigo tem como finalidade fazer uma reflexão teórica sobre as possibilidades e desafios da atuação do Serviço Social dentro da política de saúde em consonância com o Principio da Dignidade da Pessoa Humana. A metodologia utilizada foi a pesquisa bibliográfica. Contextualizando a trajetória da política de saúde no Brasil, dentro da ótica capitalista e como se dá o processo saúde/doença, abordando as lutas e movimentos para construção do Sistema Único de Saúde e suas diretrizes operacionais. Dentro desta perspectiva, o papel do Assistente Social, é de articular o seu trabalho pautado nos princípios que fundamentam o Serviço Social, romper barreiras institucionais e buscar a garantia da dignidade humana do usuário da saúde, como é preconizado na Constituição Federal de 1988. \\ Palavras-chave: Política de Saúde. Capitalismo. Sistema Único de Saúde. Constituição Federal de 1988. Dignidade Humana. Usuário. Serviço Social. \\ HEALTH AND THE PRINCIPLE OF THE DIGNITY OF THE HUMAN PERSON: POSSIBILITIES AND CHALLENGES FOR SOCIAL SERVICE PERFORMANCE}

\begin{abstract}
The purpose of this conclusion work is to make a theoretical reflection on the possibilities and challenges of the social service performance inside health policy in accordance with the principle of dignity of the human person. Bibliographical research method was used. The health policy trajectory in Brazil was put in context inside capitalist view and how the health / illness process happens, to deal with fights and movements for the creation of a national health system (known as Sistema Único de Saúde or SUS) and its operational guidelines. From this perspective, the role of the Social Worker is to articulate his or her work lined up for principles that are the basis of social service to break institutional barriers and search the guarantee of human dignity of health service user established in the Federal Constitution of 1988.
\end{abstract}

Keywords: Health Policy. Capitalism. National Health System. 1988 Federal Constitution. Human Dignity. User. Social Service.

\section{INTRODUÇÃO}

O presente trabalho discute a saúde como fundamental prioridade para que o indivíduo possa ter uma vida com dignidade. Partindo do conceito de saúde, podemos dizer que o indivíduo não constitui somente da questão biológica, mas sim dos aspectos psíquicos e sociais. Então, falar em saúde remete-se a condições de sobrevivência e é dessa premissa que partimos em discussão, considerando a Constituição Federal de 1988 que respalda esse conceito como questão de Dignidade Humana.

Apresenta como hipótese a possibilidade de trazer o Serviço Social como contribuinte para a execução da política de saúde mediante a forma gestão do SUS, elencando os aspectos históricos 
da política de saúde no cenário brasileiro, como ela se desenvolve e qual o papel do Serviço Social neste impasse.

A escolha do tema deste trabalho surgiu a partir de reflexões a respeito da saúde como principio da dignidade humana, e as possibilidades e desafios do trabalho do Assistente Social para a efetivação da saúde como direito garantido constitucionalmente.

Mediante a afirmação acima, pode-se dizer que o Assistente Social mostra-se fundamental na execução da política de saúde, pautado no Projeto Ético-Político, a fim de construir junto aos usuários do SUS, respostas às demandas inerentes aos serviços de saúde. Para o desenvolvimento deste trabalho a metodologia utilizada foi a pesquisa bibliográfica, pois tendo como objetivo verificar a contribuição do Serviço Social dentro da Política de saúde em consonância com o princípio da dignidade humana. A fim de fazer aproximações teóricas do tema em discussão, foram utilizados livros cujos autores tratavam de assuntos pertinentes, artigos, sites que traziam o assunto com propriedade e relevância para realização da pesquisa.

A principio foi realizada uma breve conceituação do contexto sócio-histórico da política de saúde e a ótica do capital, para o entendimento mais preciso a respeito das relações onde se desenvolveu o sistema capitalista e a necessidade das primeiras ações na área da saúde. Foi abordado, sobre a trajetória da política de saúde no Brasil, a concretização do Sistema Único de Saúde (SUS), mediante processo histórico decorrente em consonância com a promulgação da Constituição Federal de 1988. Na mesma perspectiva, tratou-se sobre o Principio da Dignidade da Pessoa Humana, inserido no texto constitucional, completando o arcabouço legal para a efetividade de uma vida digna aos usuários da saúde.

A pesquisa fundamentou-se sobre o exercício do Serviço Social na área da saúde, dentro do processo de gestão desta política, nela elencando as várias especificidades do fazer profissional, pautando-se no Projeto Ético Político do Serviço Social, e nos princípios do Código de Ética (1993).

E por fim, abordaremos a atuação profissional com relatos de experiências de assistentes sociais, que estão inseridos no campo da saúde, e como esses criam mecanismos para o enfrentamento dos desafios e as possibilidades de construir ações que possibilitam os usuários da política ter o acesso efetivo aos serviços e programas desenvolvidos na área da saúde pública.

\section{DESENVOLVIMENTO}

\section{Contextualização da saúde no cenário Constitucional brasileiro}

É necessária uma breve contextualização a partir da Revolução Industrial, em meados do século XVIII a XIX, o início do movimento sanitarista dentro da lógica do desenvolvimento capitalista.

Foi na Inglaterra nos séculos XVIII, XIX, que surgiram as primeiras práticas sanitaristas e, com o surgimento da era capitalista, as relações sociais se fizeram diferentes, em contrapartida, a medicina teve que se redefinir também, com novas práticas de acordo com a realidade vigente.

É dentro desta nova situação social, a do século XIX, com a industrialização e a urbanização, que ocorre a medicalização do ambiente, a qual se dá sob a forma de um projeto de Reforma Social que, posteriormente, se transforma em um programa de reforma sanitária, que era praticamente viável (ROSEN, 1980, p. 228).

As práticas sanitárias nesta época tomam como seu foco os grupos sociais enquanto classes, e o meio ambiente como lugar da produção capitalista e reprodução das classes sociais. Deste modo, a ótica do capital tem como base a apropriação privada de produção dos bens e consumo, e nesse contexto, a saúde não se desvincula dessa ideia, pois para a produção capitalista é necessária a força de trabalho. 
Segundo MOTA (2006, p.40), as Políticas de Proteção Social, nas quais se incluem a saúde, a previdência e a assistência social, são considerados produtos históricos das lutas do trabalho, na medida em que respondem pelo atendimento de necessidades inspiradas em princípios e valores socializados pelos trabalhadores e reconhecidos pelo Estado e pelo patronato.

Deste modo, podemos dizer que a força de trabalho é imprescindível para o desenvolvimento econômico e a produção de mais valia, pois a questão da saúde é fundamental para que haja a atividade laboral dos trabalhadores. "Saúde Pública é a ciência e a arte de prevenir a doença, prolongar a vida e promover a saúde e a eficiência física e mental" (MERHY, apud MASCARENHAS, 1987, p.24), com envolvimento entre indivíduo, sociedade e Estado.

Neste contexto, com o crescente desenvolvimento tecnológico e seus avanços na área, a saúde passa a fazer parte da ideia de bens de consumo, e as ações alavancadas na área social, se fazem como uma mera estratégia de mercado.

As ações oferecidas no campo social são ineficazes e contrárias à lógica das necessidades básicas e dos direitos sociais, e nesse contexto os cidadãos ficam a mercê de práticas médicocentradas ou focalizadas.

Com a insatisfação e a desassistência dos usuários, cria-se uma consciência política, mobilizando parte da sociedade civil, e impulsionando uma pressão na área estatal.

No cenário brasileiro, o descrédito com os usuários, emerge o movimento sanitário, a partir da politização de uma parcela da sociedade, acerca dos atendimentos à assistência e à saúde, articula-se em um campo social e político, detendo o papel de protagonista para novos acontecimentos no âmbito da política adotada pelo sistema. A saúde emerge como questão social, ao refletir a divisão do trabalho e do trabalho assalariado de acordo com Bravo apud Braga e Paula (1986, p.41-42).

Anteriormente à Carta Maior, a Seguridade Social era de cunho focalista e imediatista, a falta de iniciativas estatais na esfera social se dá por conta do ideário neoliberalista e do desenvolvimento e produção do capitalismo. A hegemonia neoliberal tem sido responsável pela redução dos direitos sociais e trabalhistas, desemprego estrutural, precarização do trabalho, e desmonte da previdência pública, sucateamento da saúde e das demais políticas sociais.

A Constituição Federal é um aparato legal avançado e com políticas certeiras, mas com o desmonte do Estado e o compromisso dos políticos com o capital estrangeiro, vem rebater fortemente, atingindo as políticas e a sua efetividade.

Há maior valorização ás relações econômicas, deixando à mercê os assuntos que atingem a grande maioria da população, empresas privadas vendem seus serviços, em substituição ao direito do cidadão de usufruir os sistemas de atenção, como o Sistema Único de Saúde, e acabam pagando por o que já é garantido na Constituição Federal de 1988.

Na concepção de Merhy [et al.] (1997,p.117), "nem os que podem comprar a atenção se sentem seguros com o cuidado que receberão. Porque o problema já é mais profundo, já faz parte de um estilo global, de uma maneira toda própria de realizar o conjunto do modelo de atenção de saúde no Brasil."

Os argumentos neoliberais buscam justificar a transferência das políticas públicas para a esfera do mercado, trazendo para uma suposta "realidade" a possibilidade do consumo e a necessidade de mérito e capacidades individuais, perdendo-se de vista a condição de direito social.

A lógica neoliberal possui um ideário econômico-político mantendo o capitalismo na sociedade contemporânea, efetivando o desmantelamento dos direitos sociais, acentuando a subalternidade dos países às populações neles existentes. No entanto, a Política Saúde no Brasil, passa por várias interfaces e arenas políticas e sociais até se concretizarem.

No contexto acerca da saúde no Brasil anteriormente à promulgação da Política de Saúde, já existiam alguns movimentos, como a criação de Institutos, leis e códigos sanitários. Em um 
segundo momento, foi criado o primeiro modelo de Política de Saúde no Brasil onde realizou-se conferências, foram criados ministérios e implementados os serviços e programas de saúde pública em nível nacional (central).

Partindo das mais variadas reviravoltas no campo da saúde, em 1988 foi promulgada a Constituição Federativa do Brasil, na qual deu um delineamento mais aprofundado às ações do Estado no que tange a política de saúde no Brasil, retratando o resultado de todo o processo desenvolvido ao longo de aproximadamente duas décadas, assim criando o Sistema Único de Saúde.

A preocupação de proteger a saúde aumentou através das épocas. No século XX, o papel do Estado alterou, sendo dever dele garantir o básico à sociedade, disciplinando entre deveres e direitos fundamentais que devam integrar a realidade social, uma vez que o direito à vida pressupõe não só direito de permanecer vivo, mas de viver dignamente.

Segundo Guerra e Emerique (2006, p. 386), o princípio da dignidade da pessoa humana impõe um dever de abstenção e de condutas positivas tendentes a efetivar e proteger a pessoa humana. É imposição que recai sobre o Estado de respeitar, proteger e promover as condições que viabilizem a vida com dignidade.

A partir da Constituição Federal de 1988, houve um avanço na questão das formulações legais ao garantir os direitos sociais, como um direito de cidadania.

A regulamentação dos artigos constitucionais referentes à saúde aconteceu por meio das leis 8.080/90 e 8.142/90.

O reconhecimento da saúde como resultado das condições econômicas, políticas, sociais e culturais, o Serviço Social passa a fazer parte do conjunto de profissões necessárias à identificação e análise dos fatores que intervém no processo saúde/doença.

O Serviço Social é uma profissão que se torna indispensável na sociedade capitalista contemporânea. A profissionalização do Serviço Social pressupõe a expansão da produção e de relações sociais capitalistas, impulsionadoras da industrialização e urbanização, que trazem, no seu verso, a "questão social" (lamamoto, 2004, p 172).

Seguindo as transformações ocorridas na sociedade, a profissão passou por várias mudanças ao longo de seu processo de consolidação, que foram permeadas por progressos e retrocessos possibilitando um novo olhar sobre a sociedade, principalmente na contemporaneidade.

Para a concretização dos programas e projetos na área da saúde, o profissional de Serviço Social materializa o seu projeto ético-político que visa objetivar e subsidiar a ação do assistente social junto às equipes interdisciplinares atuantes no Sistema Único de Saúde, favorecendo um atendimento de qualidade à população usuária do sistema nacional de saúde.

O Conselho Nacional de Saúde - CNS, através da resolução no 218/1997, reconheceu o assistente social como um dos treze profissionais de saúde em nível superior, juntamente com o biólogo, profissionais de educação física, enfermeiros, farmacêuticos, fisioterapeutas, fonoaudiólogos, médicos, nutricionistas, dentistas, psicólogos e terapeutas ocupacionais.

Nesta perspectiva, o assistente social desenvolve atividades de natureza educativa e de incentivo à participação da comunidade para atender as necessidades de coparticipação dos usuários no desenvolvimento de ações voltadas para a prevenção, recuperação e controle do processo saúde/doença. O profissional ainda planeja, assessora e executa programas e projetos vinculados à gestão das políticas.

Segundo o Código de Ética do Assistente Social de (1993) um dos princípios fundamentais do Serviço Social é o "posicionamento em favor da equidade e justiça social, que assegure universalidade de acesso aos bens e serviços relativos aos programas e políticas sociais, bem como sua gestão democrática." 
A "prática" do profissional de Serviço Social na saúde é mediada pela perspectiva da garantia de direitos sociais, tendo como eixo central a busca criativa e incessante da incorporação dos conhecimentos, articulados aos princípios dos projetos da reforma sanitária e ético-político do Serviço Social.

É dentro da relação de dever/direito que o trabalho dos assistentes sociais é uma "prática" necessária para a promoção e atenção à saúde de todo cidadão, não desprezando do dever estatal, propondo-se contribuir para a garantia destes através do fortalecimento de seus princípios de universalidade, equidade e integralidade. "Assim viabiliza-se concretizar o princípio da universalidade de acesso e equidade em relação aos direitos sociais" (MIOTTO, 2004, p.278), o que se constitui como papel do Assistente Social na construção integral desse processo.

\section{CONCLUSÃO}

Compreende-se que cabe ao Serviço Social, numa ação articulada com outros segmentos que defendem o aprofundamento do Sistema Único de Saúde (SUS), formular estratégias que busquem reforçar ou criar experiências nos serviços de saúde, que efetivem esta como um direito social de acordo com a Constituição Federal, viabilizando o trabalho do assistente social na saúde com o norte no projeto-ético político profissional e estar necessariamente articulado ao projeto da reforma sanitária.

Nesta perspectiva, o assistente social deve ter um posicionamento ético e político, conforme preconiza o Código de Ética, defendendo incansavelmente os direitos sociais e o acesso aos bens e serviços, sendo, fundamental para a emancipação do individuo e para que ele alcance dignidade garantida por lei.

O trabalho do Serviço Social é intrínseco para efetivação da política de saúde, já que os mecanismos desta se dá pelas vias institucionais e governamentais. É necessária a luta pela quebra das barreiras institucionais, afim de que a atuação do assistente social não se faça de forma presa pelo tarefismo e o imediatismo, com vistas a efetivação do direito integral do usuário do SUS.

Deste modo, o atual tema foi escolhido, com a pretensão de mostrar como o assistente social contribui efetivamente no processo saúde/doença dos usuários, pois o profissional articula seu trabalho estritamente com a Política que se configura como um dos instrumentos de sua prática profissional.

Pode-se concluir que todo o artifício de leis, gestão de políticas, profissionais capacitados e prática profissional, tem um único norte que é a garantia dos direitos civis, sociais e políticos dos segmentos da população, tendo em vista os direitos sociais e principalmente com a saúde e qualidade de vida dos cidadãos.

\section{REFERÊNCIAS BIBLIOGRÁFICAS}

BRASIL. Constituição Federativa do Brasil. Org J. Oliveira. 11ํ Ed. São Paulo: Saraiva, 1995.

BRASIL, Ministério da Saúde. Lei 8.080/90. Brasília,1990.

BRAVO, M. I. S, de. MATOS, M. C, de. Projeto Ético-Político do Serviço Social e sua Relação com a Reforma Sanitária: Elementos para o Debate. Serviço Social e saúde: Formação e trabalho profissional, [et al.], (orgs). São Paulo: Editora Cortez, OPAS,OMS, Ministério da Saúde,2006.

GUERRA, S. EMERIQUE L. M. B. O Princípio da dignidade humana e o mínimo existencial: Revista da Faculdade de Direito de Campos, Ano VII, № 9 - Dezembro de 2006. Disponível em: http://www.fdc.br/Arquivos/Mestrado/Revistas/Revista09/Artigos/Sidney.pdf acesso em: 05/08/2017. 
IAMAMOTO, Marilda Vilela. O Serviço Social na Contemporaneidade: trabalho e formação profissional. 7. ed, São Paulo: Cortez, 2004.

MERHY, Emerson. Elias. O Capitalismo e a saúde pública: a emergência das práticas sanitárias no Estado de São Paulo. 2ed: São Paulo: Papirus, 1987.

MIOTO, R C (org); NOGUEIRA, M, V R. Sistematização, Planejamento e Avaliação dos Assistentes Sociais no Campo da Saúde. 2004. p.258.

MOTA, Ana Elizabete, [et al.], (orgs) Serviço Social e saúde: Formação e trabalho profissional, São Paulo: Editora Cortez, OPAS,OMS, Ministério da Saúde, 2006. 